\title{
The study of the seasonal features of turbulence in the atmospheric boundary layer of the Southern Baikal region
}

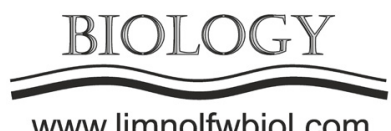

www.limnolfwbiol.com

\author{
Shikhovtsev M.Yu. ${ }^{1 *}$, Shikhovtsev A.Yu. ${ }^{2}$, Molozhnikova Ye.V. ${ }^{1}$ \\ ${ }^{1}$ Limnological Institute, SB RAS, Ulan-Batorskaya Str., 3, Irkutsk, 664033, Russia \\ ${ }^{2}$ Institute of solar-terrestrial physics SB RAS, Lermontov Str., 126a, Irkutsk, 664033, Russia
}

\begin{abstract}
This work presents the results of measuring the turbulence in the atmospheric boundary layer, which was carried out using an automated meteorological complex (AMC - 03). The measurements cover the period from 1 January to 31 December 2018.
\end{abstract}

Keywords: Baikal Natural Territory, turbulence, atmospheric boundary layer.

\section{Introduction}

Many factors affect the transfer processes and the deposition rate of impurities in the air. Among these factors, turbulence plays an important role. Thus, under strong atmospheric turbulence, due to the intensification of vertical heat flux, humidity and impurities, there may be cases of destruction of inversion layers in the atmospheric boundary layer (ABL). Some studies discussed different characteristics of turbulence in the atmosphere of the Southern Baikal region (Kovadlo et al., 2018). This work aims to study the specific kinetic turbulence at the Listvyanka site and reveal seasonal features.

\section{Materials and methods}

This work presents the results of measuring ABL turbulence from 1 January to 31 December 2018. They were carried out using an automated meteorological complex (AMC - 03) installed on the upper platform of the Large Solar Vacuum Telescope, Listvyanka.

The specific kinetic energy of turbulence served as the study value. The calculation was performed according to the ratio (1):

$$
E_{n}=\frac{\sigma_{u}^{2}+\sigma_{v}^{2}+\sigma_{w}^{2}}{2}
$$

where $\mathrm{E}_{n}$ is a specific kinetic energy of turbulent motion, $\sigma_{u}, \sigma_{v}, \sigma_{w}$ - dispersions of the components of the velocity vector in the corresponding directions. The average values of the components of wind speed $(\bar{u} \bar{u}, \bar{v} \bar{v}, \bar{w} \bar{w})$ were determined over three-minute time intervals. To identify the influence of the area forming air mass that came to the region, a series of detailed calculations was carried out using a Hybrid Single-Particle Lagrangian Integrated Trajectory Model (Draxler and Rolph) according to the 2018 archival meteorological data, Global Data Assimilation System National Oceanic and Atmospheric Administration.

We constructed 365 back trajectories of air mass motion. All trajectories were modelled according to the sampling time that corresponded to midnight of local time. The duration of the trajectories was 24 hours. Calculations were performed out for three altitudinal levels: 250, 500 and $800 \mathrm{~m}$ above ground level (AGL).

\section{Results and discussion}

Using the obtained series of $E_{n}$ values, we calculated the probability function of repeatability for different seasons of the year (Fig.). The abscissa axis indicates the values of the specific kinetic energy of turbulence, and the ordinate axis represents the repeatability.

Analysis of distributions showed that turbulence in $\mathrm{ABL}$ is the most developed in autumn and winter seasons. In autumn and winter, there is also a high frequency of events when the value of the specific kinetic energy of turbulence exceeds $7 \mathrm{~m}^{2} / \mathrm{s}^{2}$. The average values of the specific kinetic energy of turbulence in the cold season are 1.6 times higher than in the warm season. This can be caused, firstly, by the suppression of the turbulence in the warm season associated with the development of anticyclone above the lake and, secondly by the predominance of air masses from western and northwestern directions, often with high wind speeds and, hence, high energy. 


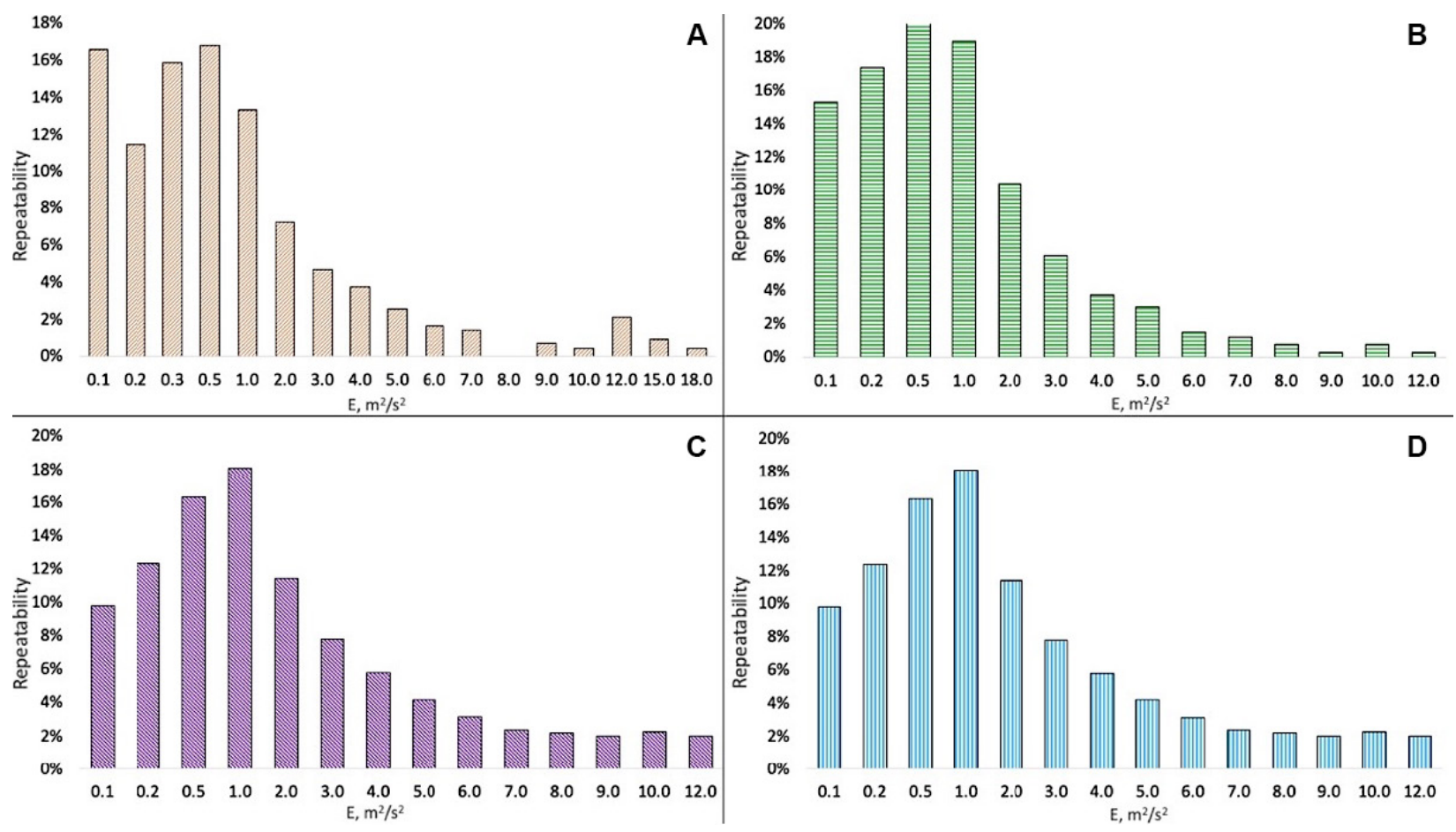

Fig. Probability functions of repeatability of the specific kinetic energy of turbulence in ABL during A - spring, B - summer, $\mathrm{C}$ - autumn, and D - winter season.

\section{Conclusions}

The obtained distributions allowed us to numerically characterize the energy structure of the atmospheric currents in the coastal zone of Lake Baikal in different seasons of the year. The average values of the specific kinetic energy of turbulence are $1.5 \mathrm{~m}^{2} / \mathrm{s}^{2}$ for the summer, $2.8 \mathrm{~m}^{2} / \mathrm{s}^{2}$ for the autumn, $2.4 \mathrm{~m}^{2} / \mathrm{s}^{2}$ for the winter, and $1.6 \mathrm{~m}^{2} / \mathrm{s}^{2}$ for the spring.

\section{Acknowledgements}

This study was carried out within the framework of the LIN SB RAS State Task No. 0345-2020-0008 "Assessment and Forecast of Ecological State of Lake
Baikal and Adjacent Territories under Conditions of Anthropogenic Impact and Climate Change" and supported by the Russian Science Foundation within the project No. 19-79-00061.

\section{References}

Draxler R.R., Rolph G.D. HYSPLIT (Hybrid Single-Particle Lagrangian Integrated Trajectory Model access via NOAA ARL READY). http://www.arl.noaa.gov/ready/hysplit4.htm

Kovadlo P.G., Lukin V.P., Shikhovtsev A.Yu. 2018. The development of the model of turbulent atmosphere on the astroplatform of Large Solar Vacuum Telescope as applied to image adaptation. Journal of Atmospheric and Oceanic Optics 31: 906-910. DOI: 10.15372/AOO20181108 